\title{
Antenatal Enrollment and Prevalence of Iron Deficiency Anemia in Specialist Hospital Akure, Nigeria.
}

\author{
Onafowokan M.A., Rufai M.O., Onadipe T.O. \\ Ogun State College of Health Technology, Ilese, Ogun State.
}

\begin{abstract}
Iron-deficiency anemia, is an important public health problem in developing countries. This study reviewed the antenatal enrollment and the prevalence of anemia among pregnant women in a specialist hospital in Akure. Hospital record was reviewed from 2008 to 2013, and records of antenatal enrolment for each month of every said year was recorded. The data was analyzed and test of significance was carried out on the varibles using statistical package for social sciences (SPSS) version 17. The result showed that year 2013 witnessed the highest enrollment of 7591 pregnant women for antenatal and prevalence of anemia among the women was very low as it was less than 0.5\%. However, year 2009 witness the highest incident of anemia. Therefore, every pregnant woman should be encouraged to enroll for antenatal care in hospitals with qualified health care professional for best pregnancy outcome.
\end{abstract}

Key words: Anemia, Antenatal, Pregnancy, Prevalence

\section{Introduction}

Anemia is a condition in which the number of red blood cells (RBCs), and consequently their oxygencarrying capacity, is insufficient to meet the body's physiological needs (1). Iron-deficiency anemia, is an important public health problem in developing countries it is estimated that about one third of the world's population suffers from anemia (2). Pregnant women owing to their high demand are valuerable to anemia(3)

Iron deficiency anemia in pregnancy may have a serious effect on the health of both the mother and the baby; anemia can increase material and infant morbidity and mortality. The mechanism leading to increase morbidity include a decreased oxygen delivery capacity and the drys function of enzymes (4)

The causes of Iron deficiency anaemia in pregnancy is a complex combination of increased iron demand, low iron intake, and chronic blood loss. (2). Many factors have been associated with the risk of irondeficiency in pregnancy e.g nutritional status, socio economic variables, culture, age, educational status, parity, spacing of pregnancies and the use of contraceptive devices.

Iron deficiency anemia is the most common nutritional disorder in the world affecting 2 billion people worldwide with pregnant women particularly a risk. The world Health organization data indicates that iron deficiency anemia is a significant problem throughout the world ranging form $1 \%$ (average of $14 \%$ )in the industrioalized countries to an average of 56\% (ranging from 35-75\%) in developing countries. The major risk groups for iron deficiency include women of childbearing age, pregnant women, and lactating post partum women.

Iron deficiency anemia is considered as a micronutrient deficiency of public health importance globally over 3.5 billion people particularly in developing countries were affected by iron deficiency (2). It occurs in 40 $80 \%$ of pregnant women in Africa. Iron deficiency anemia among pregnant women is associated with an estimated 111,000 material death worldwide yearly. The prevalence among this group in Nigeria ranges between 24 to $48 \%(5,6)$. Hence this study reviewed the antenatal enrollment and the prevalence of anaemia among pregnant women in a specialist hospital in Akure.

\section{Methodology}

This study is a retrospective study which reviewed specialist hospital, Akure record of antenatal enrollment and prevalence of iron deficiency anemia among the pregnant women. Ethical clearance was received from the hospital management before extracting record from the medical record department. Hospital record was reviewed from 2008 to 2013, and records of antenatal enrolment for each month of every said year was recorded. The data was analyzed and test of significance was carried out on the varibles using statistical package for social sciences (SPSS) version 17.

\section{Result}

Figure 1 shows that 2013 witnessed the highest antenatal enrolment of more than 7000 pregnant women while there was a plateau and relatively low enrolment in 2010 t0 2012. Also the enrolment in 2009 was also about 7000 pregnant women 
Figure 1 Antenatal enrollment

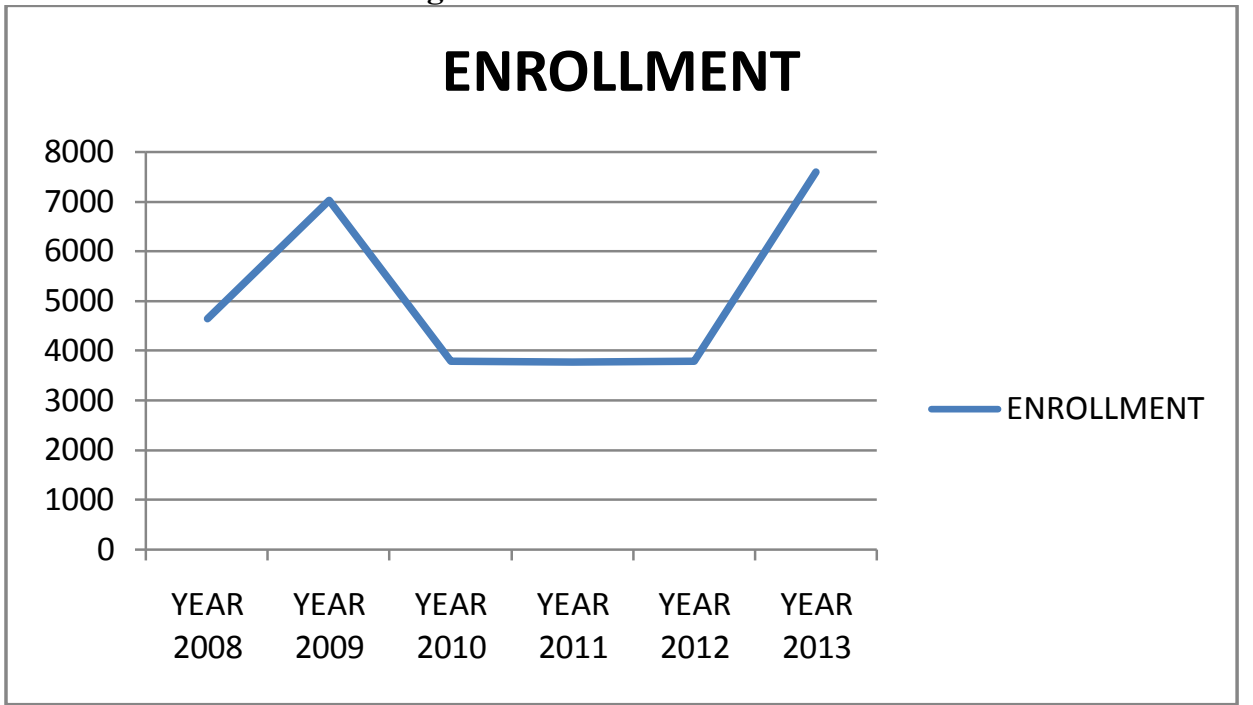

Figure 2 shows monthly enrolment through the years and it was observed that the month of July 2013 witnessed the highest enrollment followed by enrollment in April 2009 while the least enrollment was in December 2011.

Figure 2 Monthly antenatal enrollments

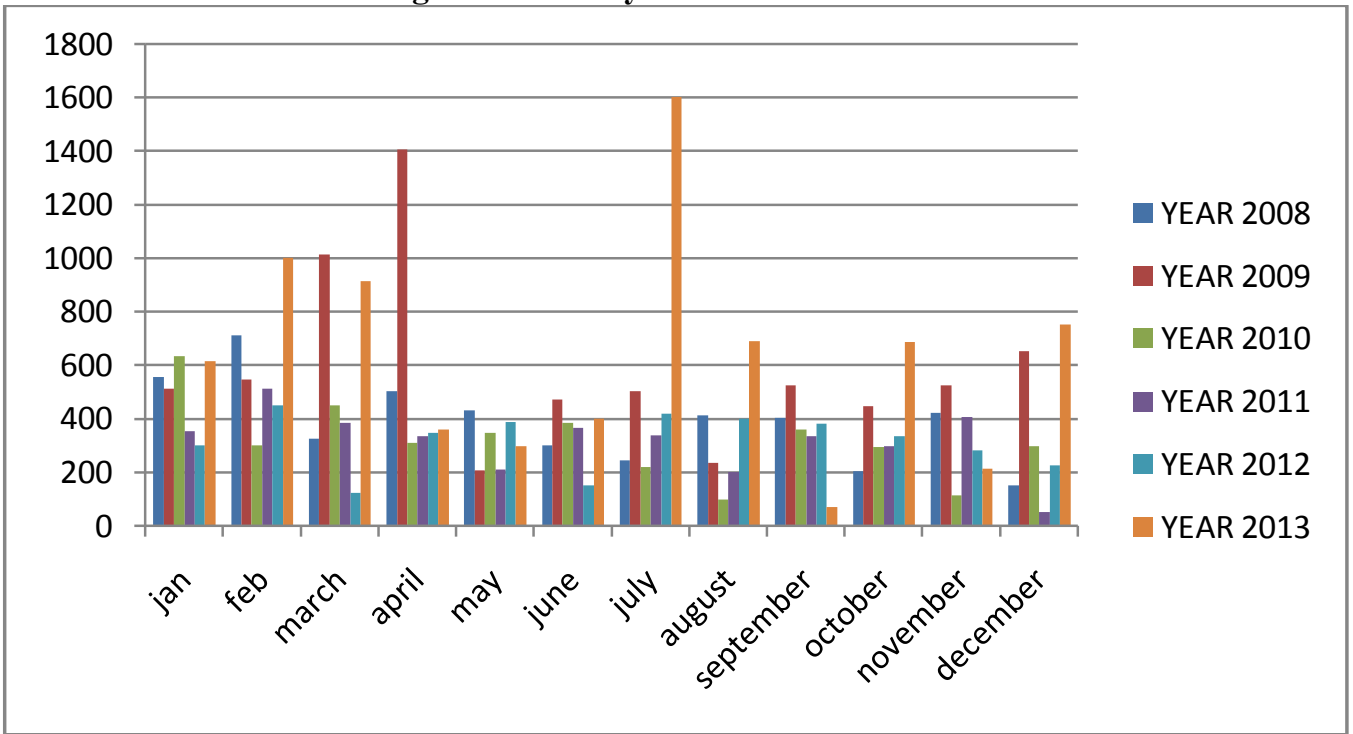

Figure 3 shows the prevalence of iron deficiency anemia and it was observed that most of the cases were found in 2009 while the least cases were in year 2008 and 2010 
Figure 3 The prevalence of iron deficiency anemia

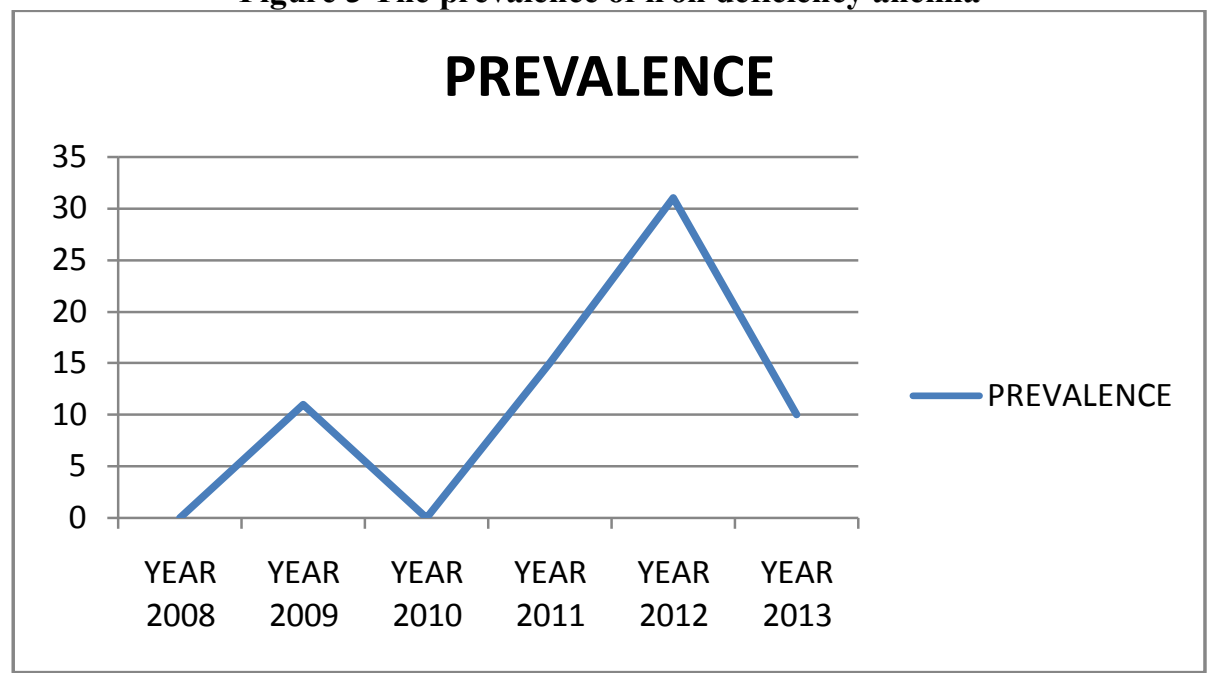

\section{Discussion}

The enrollment for antenatal among pregnant women in the specialist hospital showed a commendable turn out among pregnant women. This may be due to the fact that there is free provision of antenatal care in State. Also, there have been more enlightenment among the populace on the use of hospital where medical and health professionals can attend to the needs of the pregnant women for good pregnancy outcome.

It was also observed in the study that the prevalence of anaemia was very low among the pregnant women this may also be attributed to the fact that care and counseling was done by qualified health care professionals and the women have been adequately informed on the best nutritional and health practices for good pregnancy outcome. This agrees with earlier studies that shows that occurrence of anemia in urban centers are usually low compare to rural areas as seen in evidences in Nigeria, where it was estimated that $27.5 \%$ of pregnant women are anemic (5). Also, Emodi et al (6) reported that pregnant women that live in rural areas are the largest number of victims of iron deficiency anemia compare with those in urban areas. This may be because in many developing countries including Nigeria, poverty and hunger are serious problems facing many populations in the rural communities the intake of iron is poor due to low income, poor feeding practices and ignorance. Most times intake of dietary iron appears to be high but most of this came from non-heme sources.

\section{References}

[1]. Bertil G. The Anaemias. In Berhrman RE, Klahman RM, Jeson HB, editors. Nelson textbook of Paediatrics. 17th ed. Philadelphia: Sauders; 2004:1614 - 1616

[2]. WHO. Iron deficiency anaemia: assessment, prevention and control. A guide for programme manager. (UNICEF, UNU, WHO) 2001, pp 38

[3]. Leblanc CP, Rioux FM. Iron deficiency anaemia following prenatal nutrition intervention. Can J. Diet Pract Res. $2007 ; 68: 222$ - 5.

[4]. Choi CW, Cho WR, Park KH, Choi IK, Seo JH, Klim BS. The cut off value of serum ferritin for the diagnosis of iron deficiency in a community. Ann Hematol 2005; 84:358 - 61.78

[5]. Maziya-Dixon B, Sanusi RA, Akinyele IO, Oguntona EB, Harris FW. 2004. Iron Status of children under 5 in Nigeria: Result of the Nigeria food consumption and nutrition survey. In: proceedings of Iron Deficiency in Early life and challenges and progress. 2004

[6]. Emodi I. Azubuike JC, Nkangineme The Anaemias.In. Owerri, Nigeria KEO,editors. Paediatrics and Child Health in a Tropical Region 2nd ed: African Educational Services;2007:355-63. 